\title{
Can Integrity Replace Institutions? Theory and Evidence
}

\author{
GILAD D. AHARONOVITZ \\ NATHAN SKUZA \\ FAYSAL FAHS
}
CESIFO WORKING PAPER NO. 2730
CAtegory 6: Fiscal Policy, Macroeconomics and Growth JULY 2009

Presented at CESifo Venice Summer Institute, July 2009

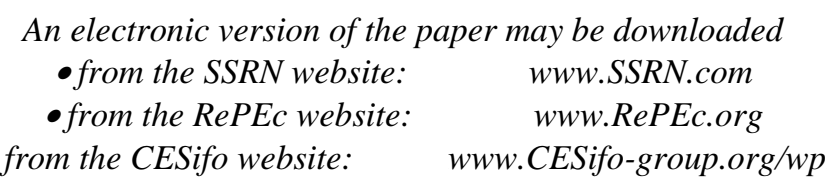




\title{
Can Integrity Replace Institutions? Theory and Evidence
}

\begin{abstract}
Institutions are important for proper economic performance, but are replaceable by trust or other social norms. We show that when proper institutions and trust are missing, integrity of the individuals can replace them. We construct a model of a transactions-based economy with contracts preceding the transactions, and show that any one of (1) institutions, (2) trust, or (3) integrity, foster economic growth. We construct data of economic performance of social groups in Lebanon, measure integrity and other values of these groups, and use this data and data from Kenya to support one of the model's predictions. Policy implications are discussed.

JEL Code: A13, C73, E19, O43, Z10.
\end{abstract}

Keywords: economic development, institutions, integrity, Lebanon, social norms, trust.

\author{
Gilad D. Aharonovitz \\ Washington State University \\ School of Economic Sciences \\ PO Box 646210 \\ USA - Pullman, WA 99164-6210 \\ aharonovitz@wsu.edu
}

\author{
Nathan Skuza \\ Washington State University \\ School of Economic Sciences \\ PO Box 646210 \\ USA - Pullman, WA 99164-6210 \\ skuzan@mail.wsu.edu
}

\author{
Faysal Fahs \\ North Dakota State University \\ 221C Morrill Hall \\ Fargo, ND 58105 \\ USA \\ faysal.fahs@ndsu.edu
}

July 2009

This paper was presented at the CESifo Venice Summer Institute 2009 workshop on Behavioral Public Economics.

The authors wish to thank Jan Musick for endless work, Mudziviri Nziramasanga, Trent Smith and Philip Wandschneider for helpful discussions and participants of PACDEV 2009 and CESifo Venice Summer Institute 2009 workshop on Behavioral Public Economics for their comments. 


\section{Introduction}

Institutions minimize transaction costs by enabling effective enforcement of contracts (North 1990), and thereby enable growth and facilitate better economic performance (see, for example, Knack and Keefer 1995; Hall and Jones 1999). When formal contract-enforcing institutions do not function well, social norms, social conventions and informal rules, which lead to trust, can foster transactions and thus increase output and growth. Zak and Knack (2001) present a theory showing that trust lowers costs of investment, thereby increasing economic performance. They use data of ethno-linguistic fractionalization (assuming that fractionalized countries enjoy less trust) and specific questions regarding trust from the World Values Survey ${ }^{1}$ to support empirical analysis (see also Knack and Keefer 1997; Guiso, Sapienza and Zingales 2004). Greif (1993) presented other social norms and social arrangements that enable transactions.

However, institutions and trust, as well as other social norms, require participation of many agents in a specific social structure, which does not always occur. This paper presents a third alternative that can replace institutions and social norms such as trust in ensuring successful transactions and better economic performance - the integrity and honesty of the individual agent (integrity and honesty serve as synonyms hereinafter, with the interpretation of a tendency of an individual not to deceive). We show that certain kinds of (1) institutions, (2) social norms and (3) moral traits, the character of the individual agent, and specifically integrity, can substitute for one another. Therefore, underdeveloped countries in which integrity level is high stand a better chance to develop compared to other underdeveloped countries. In such cases, aid can be directed at infrastructure and education rather than at constructing better institutions.

The macroeconomic literature has explored very few values of individual agents, and most of the discussion has been very general (see Guiso, Sapienza and Zingales 2006, for a literature survey). Religion gained some attention in the literature (starting with the influential work of Max Weber), but since religion includes many values, it does not permit the isolation of the effect of any particular value. Risk avoidance has received

\footnotetext{
${ }^{1}$ World Values Survey, the European Values Study Foundation and World Values Survey Association, 2006.
} 
substantial attention in the microeconomic literature, but macroeconomic growth literature has widely ignored it by assuming risk-neutrality, or identical risk avoidance among all agents. As mentioned above, trust has received some attention, but as a social arrangement (social norm) rather than as an individual's value. Only lately the study of values in economics has accelerated. Gintis (2007) shows that the endowment effect, the notion that people place a higher value on objects they own than on objects that they do not own, can lead to respect for private property, therefore supports the importance of the individual's values to economic performance. Akerlof (2007) motivates the study of values by demonstrating a possible effect of behavioral norms on the macroeconomic outcome, but without any empirical methodology or relation to institutions. Huang (2008) addresses tolerance for uncertainty, Licht, Goldschmidt and Schwartz (2007), Tabellini (2005) and Tabellini (2008a) address cultural values, and Alesina and Giuliano (2007) analyze the effect of family values.

We construct a model of a transactions-based economy. Every period the agents in the economy are randomly matched into pairs and have the opportunity to bargain and reach an agreement. After the bargaining phase, they can follow the agreement, and engage their resources (such as capital) in a transaction, or breach the agreement, if one was reached. If both agents transact, they both enjoy an increase in their amount of resources, but this is not the case if one or both agents do not transact. We show that strong institutions, in terms of contract enforceability, enable transactions, by fostering reaching agreements and then adhering to them, and that trust can take the role of contract enforcing institutions in enabling transactions. Thus, many transactions occur, each increasing the amount of productive resources and therefore allowing for higher output and growth. These conclusions are in line with existing literature. We analyze an economy without contract enforcing institutions or trust, and show that integrity can replace the two. Specifically, an economy in which all agents are honest will perform the same as an economy with good institutions or a high level of trust, while in an economy with no institutions, trust or integrity, no transactions will occur. The model yields an interesting result in the case of a heterogeneous population of honest and dishonest agents. In this case, honest agents may be cheated by dishonest agents, and thus be worse 
off than the dishonest agents, even though a purely honest economy is better off than a dishonest economy.

A major contribution of the model is in analyzing evolution over time, especially in a heterogeneous economy. We analyze the evolution of the economy assuming that the payoffs of the transactions are the return to the capital invested in these transactions. We find that an economy in which all agents are honest grows over time, while an economy in which all agents are dishonest decays over time. As for heterogeneous economies with respect to values, we find that as long as the share of capital owned by honest agents is high enough, some transactions occur. However, since dishonest agents perform better than honest agents, the share of capital owned by honest agents decreases over time, and eventually transactions cease to occur, and then the economy exhibits negative growth.

Transaction based models have been used to analyze various markets (see, for example, Mortensen and Pissarides 1994; Wheaton 1990). Axelrod (1984) analyzed the evolution of cooperation using the prisoner's dilemma as the basic transaction (see also Axelrod 1997; Tabellini 2008b). The basic transaction in our model is similar, but we add upon it a phase of negotiating an agreement (bargaining) and an agreement preceding every transaction. Since most of the economic activity in the real world is accompanied by some kind of an agreement, explicit or implicit, among its participants, this phase makes the transaction and the entire model much more realistic. Moreover, it enables the analysis of institutions and trust, and the introduction of integrity into the payoffs of the transactions, thus enabling the analysis of integrity and various other values (see, for example, Rabin 1993, for introduction of fairness into the material payoffs of a transaction). We show that institutions, trust and integrity allow for cooperation without using history-dependent strategies or reputation, assuming that agents are not aware of the history. Unlike Tabellini (2008b), we do not rely on the distance between the matched agents, but solely on the current distribution of the types of agents and their capital. Our analysis of the evolution of the economy resembles evolutionary game theory (see, for example, Friedman 1998; Samuelson 2002). However, in addition to the differences mentioned above, we do not assume an increase in the number of agents of the type receiving a higher payoff, but rather an increase in their capital, while the number of 
agents from each type remains constant. Thus, we create a macroeconomic model that allows for the analysis of the effect of institutions, norms of trust, and integrity.

A major obstacle with embedding moral traits and other values into macroeconomic research is the difficulty in measuring values. This has severely limited the literature and contributed to an absence of data. The World Values Survey, administering questionnaires directly asking people about some values, did not address many of the values that potentially affect economic performance, and the examined values suffer from a measurement problem due to the hesitancy of interviewees to identify their own perceived negative values, and from a problem of endogeneity, i.e., the concern that values might be affected by economic performance (see Guiso et al. 2006, for a description of the problem). ${ }^{2}$ This research follows the method used in Aharonovitz and Kabura (2008) in deducing values from children's stories, thus overcoming the above-mentioned problems (see also McClelland 1961). Stories are long known to reflect the values of the society (Johns-Heine and Gerth 1949; Albrecht 1956), and some claim that stories educate children and affect their values (Vitz 1990; Hakemulder 2000). Relying on these characteristics, this study uses stories collected through questionnaires to identify the values of various groups. The use of stories allows us to overcome the measurement problems in surveys of values mentioned above, and the fact that the stories chronologically precede present economic performance, i.e., the values deduced from the stories are unaffected by current economic conditions, solves the endogeneity problem.

However, since integrity is a 'third line of defense', following institutions and trust, empirical analysis requires either data regarding all three for a large set of countries or data regarding economic performance of several groups sharing the same malfunctioning institutions and low level of trust. Since we were unable to measure integrity in a large set of countries, we chose to focus on different religious groups in Lebanon. These groups share the same Lebanese institutions, which due to internal and external disputes are not well functioning, and have similar low levels of trust, but differ in their economic performance and integrity (see section 3 for data). We relied on the geographical segregation of the major religious groups in Lebanon to construct data

\footnotetext{
${ }^{2}$ Hofstede (2001) focused on measuring and analyzing work related values, but suffered from similar problems, and did not gain any influence in the macroeconomic literature.
} 
regarding the economic performance of each group. Surveys were administered to identify popular children's stories in each of the groups, from which several values, including integrity, were measured. We found heterogeneity of integrity across the groups, and a positive link between integrity and poor economic performance among these groups, thus supporting the result of the model regarding heterogeneous population. We use data regarding economic performance and values in Kenya from Aharonovitz and Kabura (2008) to further support this conclusion using regression analysis. Thus, we provide support for the conclusion of the model regarding a heterogeneous economy with respect to integrity, but we do not possess data that allows for testing the conclusions regarding pure-honest or pure-dishonest economy. We hope to be able to collect further data and to test these conclusions as well in the future.

The major contribution of this study is to provide a transaction-based model for the economy including agreements for transactions and capital, which enables analyzing the effect of contract enforcing institutions, social norms such as trust, and integrity on economic performance, introducing the effect of integrity on economic performance in the absence of contract enforcing institutions and trust, and allowing for the analysis of values. In addition, it demonstrates a procedure for measuring integrity, while characterizing economic performance and values of major religious groups in Lebanon.

The paper proceeds as follows: Section 2 presents a model of a transactions-based economy and analyzes the effect of integrity. Section 3 presents the data and empirical analysis. Section 4 concludes.

\section{The Model}

Almost every economic activity involves transaction between two or more individuals: a supplier selling goods to a producer, a worker working for a firm, individuals investing in a firm, a seller and a buyer etc., and the output of the economy is the aggregation of these transactions. We start by defining a basic economic transaction which engages resources of two matched individuals. Every period many transactions (or attempted transactions) can take place, but every unit of a resource (such as capital) can engage, or attempt to engage, in only one of these transactions every period. The total resources available for the economy can increase or decrease over the period as a result 
of the transactions, and the new amount of resources will serve the economy in the next period. We start by defining the transaction and the possible agreement for transaction, and analyze the effect of institutions, trust, and integrity on its result, and proceed by aggregating over the transaction to analyze total output and growth.

\subsection{A Single Transaction}

For simplicity, we assume that every transaction involves exactly two agents. The analysis will focus on a single resource - capital, but identical transactions can be introduced for labor (i.e., time) and other resources, where every transaction involves one unit of this resource from both sides. Before we get to the formal modeling, we will use two examples to illustrate it. Imagine, for example, a buyer and a seller matched for a transaction, in which the seller supplies a good to the buyer while the buyer pays the seller. They can both decide not to transact; in this case, there is no transaction, each retains its own resources (capital, goods, etc.) and their utility does not change. If they both decide to transact, the buyer pays for the good and enjoys the consumer's surplus, while the seller is paid and enjoys a certain profit. Hence, they both enjoy an increase in their utility. However, a third possibility is that the seller provided the good but doesn't get paid, thus the buyer enjoys a higher utility than before, while the seller enjoys a lower one. A fourth option, which is symmetric to the third, is that the buyer pays for the good while the seller does not supply it. We regard the third and fourth cases as cases in which one agent cheats the other. ${ }^{3}$

The second example is two agents who are matched for establishing a firm with an investment of one unit of capital each. Cooperation of both agents is required for the success of the firm. Thus, they can both invest in the firm and profit from the investment, or they can both abstain from investing and retain their initial capital. However, a third option is that one invests while the other does not. Since a successful transaction requires the participation of both investors, the one that invested may lose its capital. In this case, the second potential investor may require a significant premium to participate in the transaction and allow the first investor to retain its capital. Hence, we assume that the

\footnotetext{
${ }^{3}$ While in Akerlof (1970) the seller can hide the quality of the good from the buyer, but the buyer cannot deceive the seller, here both agents can deceive one another.
} 
first investor ends up with less than what he invested, while the second ends up with more than what he could have received had they both transacted to begin with.

Following these examples, we define a potential transaction as a random match of two agents, in which every agent can engage one unit of the resource (capital), and decide whether to transact $(T)$ or not $(D)$. If both decide not to transact, they each end up with 1 , the same unit they started with. If both decide to carry out the transaction, they each end up with $r$, where $r>1$, at the end of the period. If one carries out his part of the transaction while the other does not, the latter receives $r+c$ (the gain to the 'cheating' agent) while the former receives a payoff of $1-c, c>0$, which is lower than his initial capital. Note that the potential transaction is in fact a "prisoner's dilemma" type of interaction. We restrict the agents to pure strategies. See Figure I for the representation of the potential transaction as a strategic game:

\section{Figure I - A Potential Transaction}

\begin{tabular}{c|c|c|}
\multicolumn{1}{c}{} & \multicolumn{1}{c}{$D$} & \multicolumn{1}{c}{$T$} \\
\cline { 2 - 3 }$D$ & 1,1 & $r+c, 1-c$ \\
\cline { 2 - 3 }$T$ & $1-c, r+c$ & $r, r$ \\
\hline
\end{tabular}

We deviate from the common transaction based models (see, for example, Axelrod, 1984) by introducing a phase of bargaining for an agreement prior to the attempted transaction itself, i.e., the matched individuals are allowed to talk, negotiate and reach an agreement (a contract) prior to the attempted occurrence of the transaction. Since most of the real world economic activity is accompanied by an agreement among its participants, this phase makes the model more realistic than many other transactionbased models. Thus, the two individuals can agree on transacting, on non-transaction or on any pair of strategies (one for each agent) for the transaction itself. We note the four possible agreements with $[D, D],[T, D],[D, T]$, and $[T, T]$, where the first letter denotes the commitment of the first agent, and the second letter denotes the commitment of the second agent. We do not define the bargaining process itself but rather rely on the Nash axiomatic bargaining approach, treating the payoff associated with no-transaction, $(1,1)$, as the status quo. However, after the agreement was reached, both are able to choose whether to transact or not to transact regardless of the agreement (penalties for 
deviating from an agreement are introduced later). Agents are not aware of the history or the actions of other agents.

Nash equilibrium of the above game is obviously $(D, D)$. Since agents are unaware of the history of actions of other agents, there are no history-dependent strategies. Since there is no penalty for breaching the agreement, the agreement phase does not assist in executing the transaction, and regardless of the agreement the two agents reach, the transaction does not take place, and both agents end up with 1 , rather than with $r$.

\subsection{Institutions, Trust and Integrity}

Institutions are the first mechanism that can lead to a better result than $(D, D)$. We define institutions in the sense of contract enforceability. Thus, effective institutions are institutions that enforce execution of the agreement reached prior to the attempted transaction on both agents. Alternatively, institutions punish for deviating from an agreement such that the decrease in payoff due to the deviation is large enough to ensure that both agents follow the agreement. Thus, under effective institutions, the agreement would be executed, and rather than analyzing the above-mentioned strategic game the focus is on the preliminary phase of reaching the agreement.

Let us observe the four possible agreements, $[D, D],[T, D],[D, T]$, and $[T, T]$. The first agent would not agree to $[T, D]$, since by changing his own commitment to $D$ his payoff increases. Similarly, the second agent would not agree to $[D, T]$, and we are left with the possible agreements of $[D, D]$ and $[T, T]$. Both agents know that if they do not agree to $[T, T]$, the other agreement would lead to an inferior payoff (1 rather than $r$ ), and thus $[T, T]$ is the reached agreement. ${ }^{4}$ Formally, the bargaining regarding the agreement can be treated similarly to an axiomatic bargaining problem using the payoff associated with no-transaction, $(1,1)$, as the status quo, the outcome that occurs if bargaining breaks down. Similarly to the requirements of the Nash solution to the bargaining problem, Pareto Optimality rules out agreement $[D, D]$, since both agents can increase their utility by agreeing to $[T, T]$, and symmetry rules out $[D, T]$ and $[T, D]$. Thus, $[T, T]$ is the only possible solution to the bargaining problem. Alternatively, since we do not restrict the duration of the negotiations, one may treat reaching the contract as

\footnotetext{
${ }^{4}$ Notice that due to the Institutions, agents know they both would execute the agreement.
} 
an infinitely repeated game in which the agents choose the strategy to agree upon. In this type of game choosing $T$ and switching to $D$ in the rest of the periods if the other agent chooses $D$ leads to $(T, T)$, which means an agreement of $[T, T] .{ }^{5}$ Thus, good contract enforcing institutions lead to a result of $(T, T)$ and to a payoff of $r$ for each agent, rather than 1 each.

However, good institutions, formal or informal, are not always present. A possible substitute is trust, and although we focus on integrity, we present the option of trust, following Zak and Knack (2001), and show that our model is consistent with it. Zak and Knack (2001) presented a model of consumers that can save through brokers, the broker can cheat the consumer regarding the return, and the consumer can spend time verifying it. The population is socially heterogeneous, and when the social distance between the consumer and broker is smaller, verification is more efficient, i.e. the broker suffers more for cheating given the same verification time. Hence, in homogenous societies, less time is spent on verification, i.e. trust levels are higher. Trust is therefore dependent on a social arrangement that leads to more efficient verification among similar people.

We follow a simplified version of this mechanism, by defining trust as a social mechanism, in which in homogenous societies, an agent that deviates from an agreement and harms another agent is punished by the society. ${ }^{6}$ Thus, we assume that in socially homogenous population, there is a decrease of $e, e>c$, in the utility of an agent deviating from an agreement if this deviation causes damage to the other side due to social punishment, but there is no penalty for deviating if it increases the utility of the other side. Thus, $e$ captures the effect of the social arrangement among similar agents, their social ties etc., such that the members of the same social group punish the deviator. In socially heterogeneous societies, in which the social distance among the agents is larger and social ties are weaker, we assume that there is no such penalty. The payoff structure in homogenous society for every agreement is described in Figure II, where the bold text represents the Nash equilibrium for each agreement:

\footnotetext{
${ }^{5}$ Notice the similarity to the infinitely repeated version of the prisoner's dilemma.

${ }^{6}$ Our definition is, therefore, similar to institutions. We present trust to show that the model is consistent with the relevant literature (see Zak and Knack, 2001), but our major contribution is the analysis of integrity.
} 


\section{Figure II - Payoffs in Socially Homogenous Society*}

Agreement: $[D, D]$ :

\begin{tabular}{c|c|c|}
\multicolumn{1}{c}{} & \multicolumn{1}{c}{$D$} & \multicolumn{1}{c}{$T$} \\
\cline { 2 - 3 }$D$ & $\mathbf{1}, \mathbf{1}$ & $r+c, 1-c$ \\
\hline \multirow{2}{*}{$T$} & $1-c, r+c$ & $r, r$ \\
\hline
\end{tabular}

Agreement: $[T, D]$ :

\begin{tabular}{|c|c|c|}
\hline$D$ & $1-e, 1$ & $r+c-e, 1-c$ \\
\hline$T$ & $1-c, r+c$ & $r, r$ \\
\hline
\end{tabular}

Agreement: $[D, T]$ :

\begin{tabular}{c|c|c|}
\multicolumn{1}{c}{} & \multicolumn{1}{c}{$D$} & \multicolumn{1}{c}{$T$} \\
\cline { 2 - 3 }$D$ & $1,1-e$ & $\boldsymbol{r}+\boldsymbol{c}, \mathbf{1 - c}$ \\
\hline \multirow{2}{*}{$T$} & $1-c, r+c-e$ & $r, r$ \\
\hline
\end{tabular}

Agreement: $[T, T]$ :

\begin{tabular}{|c|c|c|}
\hline$D$ & $1-e, 1-e$ & $r+c-e, 1-c$ \\
\hline$T$ & $1-c, r+c-e$ & $r, r$ \\
\hline
\end{tabular}

* The bold text represents the Nash equilibrium for each agreement.

For example, if both agents agree on $[T, D]$ and agent 1 chooses $D$, his payoff decreases to 1-e or $r+c-e$ (instead of than 1 or $r+c$ ), depending on the action of the other agent. Similar considerations as with institutions rule out the agreement of agent 1 to $[T, D]$, which in the subsequent 'game' would yield 1-c, compared to 1 under the agreement of $[D, D]$. Agreement for $[D, T]$ is ruled out using similar considerations for agent 2. Among the other two agreements, the agreement of $[T, T]$ is preferred over $[D, D]$ by both agents, and thus the payoff to each one of the agents is $r$. Formally, similar to institutions above, one can treat reaching the agreement as a Nash bargaining problem, or as a repeated game, in which the payoffs are the payoffs in the Nash equilibrium which follows that agreement. In the spirit of the requirements of the Nash bargaining solution, Pareto Optimality rules out agreement $[D, D]$ and Symmetry rules out $[D, T]$ and $[T, D]$. Hence, $[T, T]$ is the only possible solution to the bargaining problem (for a repeated game, choosing $T$ by both agents is a possible result of such a game). Thus, the social arrangement of punishing for deviations allows for trust, i.e. knowing that an agreement would be followed, and thus enables an agreement for 
transacting and execution of this agreement, similarly to good institutions. Obviously, in socially heterogeneous societies, where this punishment mechanism does not exist, regardless of the agreement the two agents reach, the transaction does not take place. Therefore, both agents end up with 1 , rather than with $r$. Other mechanisms of social norms, in which an agent deviating from an agreement or contract is punished by a third party (see, for example, Greif 1993) can be modeled in a similar way. Thus, the model is consistent with the literature regarding the causes and effects of trust and with other social norms.

Both institutions and social norms such as trust require cooperation, i.e. participation of more than one agent in their formation, which is not always available. However, integrity (or honesty, which serves her as a synonym), a characteristic of an individual, can perform the same role without such cooperation. We define an honest agent as an agent that does not like to lie, i.e., suffers a decrease of $d$ in her utility $\left(d>_{C}\right)$ whenever she commits to one action but performs another, regardless of whether the other side suffered a loss due to the deviation. A dishonest agent does not suffer from not carrying out his commitment. Hence, honesty is a personal characteristic (a moral trait). Note that we are not interested in the origin of this characteristic, nurture or nature, genetic, religious, induced by parents etc., but simply assume the existence of honesty or dishonesty in any given agent. Agents are unaware of the type of the agent they are matched with, but are aware of the share of each type in the population. The population is large, such that the type of a given agent does not affect the probabilities of being matched with each type.

We proceed with the analysis of an economy with no institutions and no trust. While proposition 1 is intuitive and proposition 2 is semi-intuitive as well, they serve as a basis for proposition 3 and especially for proposition 4, which provide a deeper understanding of the evolution of such economy over time.

Proposition 1: Assume an economy with no institutions and no trust. If all the agents are honest, the outcome of every match is $(T, T)$, and the utility to every individual is $r$. If all the agents are dishonest, the outcome of every match is $(D, D)$, and the utility to every individual is 1 . 
Proof: If all agents are honest, the payoffs and the Nash equilibrium for the possible agreements are described in Figure III below:

Figure III - Payoffs with Integrity of Both Agents*

Agreement: $[D, D]$ :

\begin{tabular}{c|c|c|}
\multicolumn{1}{c}{$D$} & \multicolumn{1}{c}{$D$} \\
\cline { 2 - 3 }$D$ & $\mathbf{1}, \mathbf{1}$ & $r+c, 1-c-d$ \\
\cline { 2 - 3 }$T$ & $1-c-d, r+c$ & $r-d, r-d$ \\
\cline { 2 - 3 } & &
\end{tabular}

Agreement: $[T, D]$ :

\begin{tabular}{c|c|c|}
\multicolumn{1}{c}{} & \multicolumn{1}{c}{$D$} & \multicolumn{1}{c}{$T$} \\
\cline { 2 - 3 }$D$ & $1-d, 1$ & $r+c-d, 1-c-d$ \\
\cline { 2 - 3 }$T$ & $1-c, r+c$ & $r, r-d$ \\
\cline { 2 - 3 }$T$ & &
\end{tabular}

Agreement: $[D, T]$ :

\begin{tabular}{c|c|c|}
\multicolumn{1}{c}{} & \multicolumn{1}{c}{$D$} & \multicolumn{1}{c}{$T$} \\
\cline { 2 - 3 }$D$ & $1,1-d$ & $r+c, 1-c$ \\
\cline { 2 - 3 }$T$ & $1-c-d, r+c-d$ & $r-d, r$ \\
\cline { 2 - 3 } & &
\end{tabular}

Agreement: $[T, T]$ :

\begin{tabular}{c|c|c|}
\multicolumn{1}{c}{} & \multicolumn{1}{c}{$D$} & \multicolumn{1}{c}{$T$} \\
\cline { 2 - 3 }$D$ & $1-d, 1-d$ & $r+c-d, 1-c$ \\
\cline { 2 - 3 }$T$ & $1-c, r+c-d$ & $\boldsymbol{r}, \boldsymbol{r}$ \\
\hline
\end{tabular}

* The bold text represents the Nash equilibrium for each agreement.

Similar to the argument for trust, agreements $[D, T]$ and $[T, D]$ are ruled out (note that the payoffs of the Nash equilbria of the two agreements are identical to the case of trust). $[T, T]$ is preferred to $[D, D]$, and thus $[T, T]$ would be the reached agreement, and $r$ is the payoff of each of the two honest agents.

If the two agents are dishonest, there is no loss of utility $(d)$ due to any deviation from an agreement. Therefore, regardless of the reached agreement, the proceeding payoffs of the attempted transaction are those described in Figure I. Accordingly, similarly to the case of no institutions, the agreement is merely a 'cheap talk', the Nash equilibrium is $(D, D)$ and the payoffs to both agents are 1 .

Q.E.D.

Note that the payoffs in a pure honest society are similar to those of a socially homogenous society, i.e., a society with trust, and that a pure dishonest society is similar to a socially heterogeneous society. The contribution of integrity in these cases is the 
motive behind the payoffs. However, a major contribution of integrity is the case of heterogeneous society with respect to values, which cannot be represented using social heterogeneity.

Proposition 2: Assume an economy with no institutions and no trust. If the population is heterogeneous with respect to integrity, a dishonest agent obtains an equal or greater payoff than an honest agent, when they are matched with one another.

Proof: Regardless of the agreement reached, a dishonest agent chooses $D$ in the attempted transaction (as evident from Figure I, $D$ is a strictly dominant strategy).

An honest agent chooses the strategy she agreed upon (as evident from Figure III, for every agreement, the payoffs of an honest agent that follows what she agreed upon are higher than if she does not follow the agreement, regardless of the action of the other agent). Denote the probability of encountering an honest agent with $p$. Since all the honest agents face the same probability of meeting another honest agent and the same payoffs schedule, their decisions are identical. If an honest agents find it optimal to agree on $T$ in the agreement phase, and she encounters another honest agent, the result is ( $T, T$ ), and her payoff is $r$. However, if she encounters a dishonest agent and chooses $T$, her payoff is 1-c (since the other agent chooses $D$ ). Thus, her expected payoff is $p \times r+(1-p) \times(1-c)$.

If honest agents find it optimal to choose $D$, a match of an honest agent with another honest agent will result in $(D, D)$ and payoffs of 1 for each agent. A match with a dishonest agent has an identical result. Thus, the payoff of an honest agent in this case is 1. Therefore, an honest agent would find it optimal to agree to transact (and therefore to transact) if and only if $p \times r+(1-p) \times(1-c) \geq 1$, i.e., if $p$ and $r$ are high enough.

Thus, if $p \times r+(1-p) \times(1-c) \geq 1$, an honest agent agrees to $T$ and actually chooses $T$, and thus enjoys a payoff of $r$ or 1-c, when matched with an honest or dishonest agent, respectively. A dishonest agent, in this case, gets a payoff of $r+c$ or 1 , when matched with an honest or dishonest agent, respectively, i.e. a greater payoff than the honest agent. If $p \times r+(1-p) \times(1-c)<1$, honest agents agree on $D$ and choose $D$, and thus everyone gets a payoff of $1 . \quad$ Q.E.D. 
Thus, when there are no institutions and trust, but all agents are honest, every match results in a transaction, while if all agents are dishonest, a match will end up with no transaction. In a heterogeneous economy with respect to integrity, if the probability of meeting an honest agent, $p$, is high enough (given the payoffs), a match that involves two honest agents will result in a transaction, but other matches will result in no transaction or one agent cheating the other. If the probability of meeting an honest agent is low, matches will end up with no transactions, similar to the economy of dishonest agents.

\subsection{A Single Period and the Evolution of the Economy over Time}

There is one good in the economy that can be used as capital or for consumption

purposes. Denote with $K_{t}$ the aggregate stock of capital at the beginning of period $t$. The capital is owned (separately) by the many different agents (honest and dishonest). Denote with $K_{t}^{H}$ the aggregate capital owned by honest agents in the beginning of period $t$ and with $K_{t}^{D}$ the aggregate capital owned by dishonest agents in period $t$. Throughout the period the agents are randomly matched with each other, and every match can engage in a single transaction of the type mentioned above, which involves one unit of capital from each side. The payoffs of a transaction are the output stemming from this capital. For example, in case an attempted transaction ends with $(T, T)$ every unit of capital turns into $r$ units (including the initial unit), while if the attempted transaction ends with $(D, D)$, every unit of capital becomes 1 unit of output. An agent that owns $k$ units of capital would be matched $k$ times, such that all the units of capital would be able to engage in transactions. Accordingly, since every transaction requires 2 units of capital (one from each agent), there are $K_{t} / 2$ attempted transactions in the period. The payoffs from all the transactions are realized at the end of the period, followed by consumption. Every agent consumes a share 1-s of the payoffs received and saves $s$ of these payoffs for the following period, where $1 \geq s>0, s r>1$. The saved payoffs serve as the capital for the subsequent period.

The agents are not aware of the type of agent (honest or dishonest) they are matched with, but are aware of the overall amount of agents from each type and the total capital owned by each type, and thus are aware of the probabilities of being matched with each type of agent. Accordingly, the probability of encountering an honest agent in 
period $t$ is $p=K_{t}^{H} /\left(K_{t}^{D}+K_{t}^{H}\right)$. We assume that there are many agents in the economy, such that the type of a certain agent does not affect $p$ this agent faces.

Proposition 3: Assume an economy with no institutions and no trust. If all the agents are honest, the growth rate of the capital stock is positive and equals $s r-1$. If all the agents are dishonest, the growth rate is negative and equals $s-1$.

Proof: According to proposition 1, if all agents are honest, every match ends with a transaction, i.e., $(T, T)$, and thus every unit of capital turns into $r$ units of output. Therefore, a capital stock of $K_{t}$ becomes output of $r K_{t}$, out of which $s r K_{t}$ units are saved for the next period, i.e., $K_{t+1}=s r K_{t}$. Therefore, the growth of the capital stock (and output) is $s r-1$, which is positive since $s r>1$.

According to proposition 1, if all agents are dishonest, every match ends with both sides choosing $D$, and thus the output from every unit of capital engaged in the attempted transaction is 1 . Therefore, a capital stock of $K_{t}$ becomes output of $K_{t}$, out of which $s K_{t}$ units are saved, i.e., $K_{t+1}=s K_{t}$. Therefore, the growth rate of the capital stock, and therefore of output, is negative $(s-1)$ Q.E.D.

Proposition 4: Assume an economy with no institutions and no trust. If the population is heterogeneous with respect to integrity and the distribution of capital is such that honest agents choose to transact, the share of the capital owned by honest agents out of the total capital is decreasing over time, such that honest agents find it less profitable to agree on $T$ and to transact over time. If the distribution of capital is such that honest agents choose not to transact, the growth rate of the output is negative and equals $s-1$.

Proof: The probability of being matched with an honest agent in period $t$ is $p_{t}=K_{t}^{H} /\left(K_{t}^{D}+K_{t}^{H}\right)$. As in proposition 2, honest agents agree on $T$ and choose $T$ if and only if the distribution of capital is such that $p_{t}$ is high enough to satisfy $p_{t} \times r+\left(1-p_{t}\right) \times(1-c)>1$. In this case, as in proposition 2 , the average output out of one unit of capital held by an honest agent is $p_{t} \times r+\left(1-p_{t}\right) \times(1-c)$, and since $s$ of it is saved $K_{t+1}^{H}=s K_{t}^{H}\left(p_{t} \times r+\left(1-p_{t}\right) \times(1-c)\right)$. As in proposition 2, the average output out of one unit of capital held by a dishonest agent is $p \times(r+c)+(1-p) \times 1$, and since $s$ of 
it is saved $K_{t+1}^{D}=s K_{t}^{D}\left(p_{t} \times(r+c)+\left(1-p_{t}\right) \times 1\right)$. Thus, by substituting $K_{t+1}^{D}$ and $K_{t+1}^{H}$, one can get $\frac{K_{t+1}^{D}}{K_{t+1}^{H}}=\frac{K_{t}^{D}}{K_{t}^{H}}\left(1+\frac{c}{p_{t} \times r+\left(1-p_{t}\right) \times(1-c)}\right)>\frac{K_{t}^{D}}{K_{t}^{H}}\left(1+\frac{c}{r}\right)$. Therefore, as long as $p$ is such that honest agents agree to transact, $K_{t+1}^{D} / K_{t+1}^{H}$ is increasing unboundedly. Note that $p_{t+1}=\frac{K_{t+1}^{H}}{K_{t+1}^{D}+K_{t+1}^{H}}=\frac{1}{1+K_{t+1}^{D} / K_{t+1}^{H}}$, and therefore, as long as honest agents agree on $T, p_{t} \underset{t \rightarrow \infty}{\longrightarrow} 0$. Thus, both $p$ and the payoff to honest agents, $p \times r+(1-p) \times(1-c)$, decrease over time. Since $(1-c)<1$ and $r>1$, there exists $\hat{p}$ such that $\hat{p} \times r+(1-\hat{p}) \times(1-c)=1$. Eventually $p_{t}$ decreases below $\hat{p}$, and honest agents prefer not to agree on $T$.

Once $p_{t}$ is below $\hat{p}$, honest agents agree on $D$ in the agreement phase and do not transact. Dishonest agents do not transact as well, so that all transactions end up with $(1,1)$. Therefore, the output from every unit of capital is $1, s$ out of it is saved for the next period and thus the capital stock is diminishing at a rate of 1-s. Note also that $K_{t+1}^{H}=s K_{t}^{H}$ and $K_{t+1}^{D}=s K_{t}^{D}$, thus $p$ is not changing over time from that period. Therefore, $p$ remains below $\hat{p}$ for all the following periods, and no transactions would take place in the following periods. Q.E.D.

Proposition 3 describes the growth paths of an economy with complete integrity, where all agents are honest, compared to the deterioration of an economy without integrity. Proposition 4 describes the deterioration in economic performance of a heterogeneous economy with respect to integrity. While in initial periods, transactions may occur and the capital and output may increase, since dishonest agents get higher payoffs and acquire capital, the probability of an honest agent to be matched with a dishonest agent is increasing over time, and eventually the honest agents would choose not to transact. From that point onwards, there are no transactions in the economy, and it follows the deterioration path of the economy without integrity.

Evolutionary game theory analyzes the stability of a certain group to the introduction of few mutants, where in some cases the mutants' payoff is higher and the mutants' population increases and takes over the rest of the population. As evident from 
proposition 4, a pure-honest economy is not stable for the introduction of a dishonest agent under the assumptions we have used. However, one should note that if the number of dishonest agents is very small, and the number and the identity of these agents are not changing over time but only their capital, the assumption that the other agents do not know who are the dishonest agents is no longer plausible. One may consider, for example, a single dishonest agent introduced to an honest economy. According to proposition 4 his capital is increasing over time relative to the capital of the other agents, eventually making the probability of encountering him high enough to deter from any transactions in the economy. However, since it is the same single agent in all the periods, it is reasonable to assume that eventually the other agents learn about his identity, cease transacting with him, but continue transacting with one another. Thus, by allowing for the exclusion of small groups that are not changing over time from the assumption of anonymity, the use of capital creates a certain stability of an honest economy.

One can easily incorporate labor into the model by introducing a total amount of time available for work every period, equally distributed among the agents. Agents are matched in a similar way to the above, investing either one unit of labor or one unit of capital in every transaction, the payoff structure is identical and the payoffs can be used for consumption or for savings as capital. Alternatively, a transaction may require both capital and labor. One can also introduce technological change (an increase in $r$ over time) in a learning-by-doing style mechanism. The main results regarding the differences between an economy in which all agents are honest to an economy in which they are not are maintained, although the renewability of the labor resource over time creates a lower bound for the output of the latter economy.

\section{Data and Empirical Analysis}

This section provides empirical support for the effect of honesty and integrity over economic performance in economies that are heterogeneous with respect to integrity. As mentioned above, since integrity is a 'third line of defense' for the execution of transactions, empirical analysis of honesty and economic performance should focus either on cross-country analysis for countries in which institutions are weak and trust level is low, or on different ethnic, religious or other groups within a given country, in 
which institutions are weak and trust levels are low. We chose to focus on the latter, and constructed indicators for economic performance, trust and integrity for five religious groups in Lebanon, a country in which internal and external forces have weakened its institutions. Kaufmann, Kraay and Mastruzzi (2008) ranked Lebanon in the 30 percentile with respect to Rule of Law (which includes contract enforceability), with a score of 0.66 on a scale of -2.5 to 2.5. Since we found that trust levels are low (see below), which is consistent with the ethno-linguistic characteristic of the country, we can analyze the link between integrity and economic performance. We also support our theoretical findings with evidence from Kenya.

The main religious groups in Lebanon are Shiite Muslim, Sunni Muslim, Maronite Christian, other Christians and Druze. We grouped the Maronite Christians and the other Christians into one group (due to the inability to geographically distinguish between the two). We also separated the Shiite Muslims into two groups, due to geographic separation to two areas, the Southern part of Lebanon and the Beka, and different characteristics of the population in these areas. Thus, we have five different groups: Shiite Muslim (Beka), Shiite Muslim (South), Sunni Muslim, Christian and Druze.

\subsection{Economic Performance}

Religious identity is a sensitive issue in Lebanon; consequently, the government does not release data that directly identifies individuals' religious associations or the economic conditions of members of various religious groups. However, there is a strong association between geographical location and religious groups, which we utilized in order to construct indices for the various groups. El-Khoury and Panizza (2005) provides data based on the 1996 Lebanese Population Housing Survey that include the shares of Druze, Muslim-Shiite, Muslim-Sunni, Maronite Christian and other Christians in the population for each of the 26 districts ('kadas'). We relied on their data to classify each of these districts to one of the religious groups mentioned above, based on the religion of the majority of the population, dropping any district in which there is no clear majority associated with a certain religious group.

Economic indices were extracted from the Demographic Characteristics and Socio-Economic Situation in Lebanon (2001), a report compiled from the Public Housing 
Survey of 1996, the Census of Building and Institutions 1996, and supplemental sources, by the Lebanese Ministry of Social Affairs in cooperation with United Nations Development Program (UNDP). The report provides many indicators for each one of the districts, from which we focus on three categories: housing, education, and income related indicators. The data provided classified households into five groups with respect to these indicators, ranging from very low to very high, where ranking of very low and low level of satisfaction are considered "deprivation" levels of basic needs, and reports the percentage of the population in each district that falls in each of these levels of satisfaction.

We used the above mentioned data to compute indices of economic performance for each of the five identified religious groups. For every district and for every category (housing, education, and income), we calculated the percentage of population at deprivation level (by summing the share of low and very low). For every religious group, we averaged the shares of population in deprivation level, weighted by population, in the districts associated with that particular group. Thus, we calculated deprivation indices for each group for the three categories (the share of the population with dissatisfactory level of that category), representing economic performance of the group, such that a lower indicator represents better economic performance. See Table 1 for the districts of each group and the calculated indicators.

Table 1 - Deprivation Indicators for Groups in Lebanon

\begin{tabular}{|c|c|c|c|c|}
\hline Group & Districts & Housing & Education & Income \\
\hline & & $\begin{array}{l}\text { \% population } \\
\text { with } \\
\text { unsatisfactory } \\
\text { conditions }\end{array}$ & $\begin{array}{l}\text { \% population } \\
\text { with } \\
\text { unsatisfactory } \\
\text { conditions }\end{array}$ & $\begin{array}{l}\text { \% population } \\
\text { with } \\
\text { unsatisfactory } \\
\text { conditions }\end{array}$ \\
\hline Christian & $\begin{array}{l}\text { El-Matn, Jbeil, Kesrouan, Bsharri, El- } \\
\text { Batroun, Zghorta, Jezzine, El-Koura }\end{array}$ & 20.6 & 25.7 & 30.5 \\
\hline Druze & Aley & 19.7 & 23.1 & 35.4 \\
\hline Muslim/Shiite (Beka) & Baalbak, Hermel & 34.9 & 46.5 & 59.8 \\
\hline Muslim/Shiite (South) & Tyre, Bint Jbeil, Marjeyoun, Nabatieh & 29.4 & 44.0 & 57.7 \\
\hline Muslim/Sunni & $\begin{array}{l}\text { Akkar, El-Menie-Dennieh, Tripoli } \\
\text { Sidon, Hasbaya }\end{array}$ & 33.3 & 47.8 & 54.9 \\
\hline
\end{tabular}

One can easily notice the differences among the groups and the correlations across the indices. The indicators for all the Muslim groups are significantly higher than 
those of the Christians and Druze, representing a larger share of the population of the Muslim groups with unsatisfactory conditions, i.e. suffers from poorer economic performance.

\subsection{Values}

Since stories reflect the values of the society (Johns-Heine and Gerth 1949; Albrecht 1956) and shape the values of the younger members of the society (Vitz 1990; Hakemulder 2000), following Aharonovitz and Kabura (2008), we have used children's stories to infer the values of each of the religious groups (see also McClelland 1961). We interviewed respondents from each of the five groups (by telephone), asking each responder to name and narrate popular children stories, thus collecting 126 popular stories. $^{7}$ Although we are interested only in integrity and trust, we used the stories to infer various other values that may affect economic performance, to allow for future use. A research assistant and two of the researchers evaluated each story with respect to twelve values (hard work, entrepreneurship, risk taking, collaboration, leading others, altruism, responsibility to other group members, law obedience, just reward, integrity, trust, and justice/morality), without knowing to which group the story belongs. Each story received a score for each value (i.e., twelve scores): -1 for opposing the value, 1 for some support, 2 for strong support, and NA for not addressing the value, with a majority rule being used in case of differences in the evaluations. For each group, the indices for the twelve values were constructed as the average over the scores of these values for each of its stories. See Appendix 1 for a list of the questions used for scoring.

Out of the above mentioned values, leading others and law obedience were addressed in less than three stories for at least two of the groups, and thus are not reported. Justice/morality was addressed in only one story for one of the groups (Druze), thus we chose to report it, but to be cautious in using it. Table 2 describes the results:

\footnotetext{
${ }^{7}$ Since we were asking to name and narrate popular stories, a small sample in sufficient to identify representative stories.
} 
Table 2 - Values of Groups*

\begin{tabular}{lcccccccccc}
\hline & $\begin{array}{l}\text { Hard } \\
\text { work }\end{array}$ & $\begin{array}{c}\text { Entrepre } \\
\text { neurship }\end{array}$ & $\begin{array}{c}\text { Risk } \\
\text { taking }\end{array}$ & $\begin{array}{c}\text { Collabo } \\
\text { ration }\end{array}$ & $\begin{array}{c}\text { Altruism Responsi } \\
\text { bility to } \\
\text { other } \\
\text { group } \\
\text { members }\end{array}$ \\
\hline Christian & 1.4 & 0.5 & -0.3 & 1.1 & 1.4 & 1.4 & 1.6 & $\mathbf{0 . 9}$ & $\mathbf{0 . 3}$ & 2.0 \\
Druze & 1.3 & -0.2 & -0.3 & 0.3 & 0.6 & 1.0 & 0.6 & $\mathbf{- 0 . 1}$ & $\mathbf{- 0 . 4}$ & $-1.0^{* *}$ \\
$\begin{array}{l}\text { Muslim/Shiite } \\
\text { (Beka) }\end{array}$ & 1.2 & 0.3 & -0.1 & 0.9 & 1.2 & 1.5 & 1.3 & $\mathbf{1 . 4}$ & $\mathbf{0 . 5}$ & 2.0 \\
$\begin{array}{l}\text { Muslim/Shiite } \\
\text { (South) }\end{array}$ & 1.5 & 0.0 & -0.1 & 0.8 & 1.3 & 1.9 & 0.9 & $\mathbf{0 . 6}$ & $\mathbf{- 0 . 6}$ & 1.7 \\
Muslim/Sunni & 1.3 & -0.3 & 0.0 & 0.1 & 1.2 & 1.4 & 1.0 & $\mathbf{1 . 0}$ & $\mathbf{- 0 . 5}$ & 2.0 \\
\hline
\end{tabular}

* 2 - strong support; 1 - some support; 0 - no support; -1 opposing the value.

** Based on only one story.

Trust levels are relatively low, with values of -0.6 to 0.5 . Thus, trust cannot replace institutions, and we can focus on integrity. Integrity levels vary between -0.1 (Druze) and 1.4 Muslim/Shiite (Beka), and their relation to economic performance will be presented in the next sub-section. Levels of justice/morality, which may be equivalent to integrity, vary from -1.0 (Druze) to 2.0, but the observation of -1.0 is based on only one story, while the remaining four observations provide very little variation.

\subsection{Correlations}

We have calculated the correlations and found that the correlation of integrity with 'housing' is $\mathbf{0 . 7 5}$, with 'education' is $\mathbf{0 . 6 9}$ and with 'income' is $\mathbf{0 . 5 5}$. One can easily notice the positive correlation between integrity and all these deprivation indicators, i.e., being more honest is associated with poorer economic performance.

Causality between the indicators and integrity can run in only one direction. The economic performance indictors represent the conditions during the 1990s, while many of the stories used to measure integrity are much older. Since the stories and the inferred values predate the economic indicators, there is no endogeneity between the two, and causality can run from integrity to current economic performance, but economic performance cannot be causal to the any of the values.

Within a framework of a given country, internal trade and economic integration tend to be very high, compared, for example, to international trade (the border effect). Thus, we can expect many matches and attempted transaction among the different 
groups. Since integrity varies across the different groups, the economy fits propositions 2 and 4 regarding a mixed economy. The correlations that were found are in line with proposition 2, since the groups with less integrity perform better than the groups with more integrity, i.e., groups with more dishonest people perform better since many of them manage to cheat people from other groups with higher levels of honesty. One may also consider it as simple interactions between the groups, leading to a similar result. Lebanon was once known as "Switzerland of the East". Although a civil war, that affected the economy significantly, ended at 1990, Lebanon finds it hard to recover and to return to its previous status, in-line with proposition 4 regarding the deterioration of a heterogeneous economy with respect to integrity. However, the proposition refers to long-term evolution; thus, many more years may be required in order to verify whether the economy indeed behaves in-line with the proposition. We refrain from regression analysis of Lebanon since we have only five observations, but present regression for Lebanon and Kenya together, see subsection 3.5.

\subsection{Evidence from Kenya}

Aharonovitz and Kabura (2008) provides data regarding economic performance and values of seven tribes in Kenya. Out of this data, Table 3 provides the economic indicators constructed there, and the findings regarding integrity and trust. Notice that for all indicators besides infant mortality, higher indicator represents better economic performance.

Table 3 - Economic Performance Indicators and Values for Tribes in Kenya

\begin{tabular}{|c|c|c|c|c|c|c|c|c|}
\hline Tribe & $\begin{array}{c}\text { Infant } \\
\text { Mortality } \\
\text { Rate }\end{array}$ & Education & Family Size & $\begin{array}{c}\text { External } \\
\text { Employment }\end{array}$ & $\begin{array}{l}\text { Electricity, } \\
\text { Piped Water } \\
\text { and Sewage }\end{array}$ & House Roof & Integrity $^{*}$ & Trust $^{*}$ \\
\hline & $\begin{array}{l}\text { (per } 1000 \\
\text { live births, } \\
2007 \text { ) }\end{array}$ & $\begin{array}{c}\text { (\% of } \\
\text { population } \\
\text { with primary } \\
\text { and above } \\
\text { education, } \\
1999)\end{array}$ & $\begin{array}{c}\text { (\% of } \\
\text { population } \\
\text { with 1-3 } \\
\text { members, } \\
1999)\end{array}$ & $\begin{array}{c}\text { (\% of } \\
\text { population } \\
\text { employed } \\
\text { outside the } \\
\text { family, } \\
1999)\end{array}$ & $\begin{array}{c}\text { (average \% } \\
\text { of } \\
\text { households } \\
\text { with access } \\
\text { to, 1999) }\end{array}$ & $\begin{array}{c}\text { (\% of } \\
\text { population } \\
\text { with sheet } \\
\text { metal, tiles } \\
\text { or concrete } \\
\text { roof, 1999) }\end{array}$ & & \\
\hline Kalenjin & 53.0 & 51.1 & 32.5 & 33.5 & 11.0 & 58.7 & 0.79 & -1.00 \\
\hline Kamba & 55.9 & 54.9 & 31.0 & 29.1 & 8.3 & 67.4 & 0.07 & -0.83 \\
\hline Kikuyu & 35.0 & 71.4 & 45.9 & 38.8 & 20.1 & 95.9 & -0.47 & -1.00 \\
\hline Kisii & 61.2 & 58.0 & 27.9 & 21.5 & 4.4 & 69.8 & -0.17 & -0.89 \\
\hline Luhya & 104.9 & 54.6 & 33.4 & 24.1 & 5.7 & 57.3 & 0.14 & -0.70 \\
\hline Luo & 125.8 & 52.9 & 40.8 & 23.8 & 8.4 & 54.3 & 0.08 & -0.82 \\
\hline Meru & 46.1 & 50.6 & 37.9 & 24.5 & 19.8 & 88.4 & 0.11 & -0.88 \\
\hline
\end{tabular}

* 2 - strong support; 1 - some support; 0 - no support; -1 opposing the value. 
Institutions in Kenya are weak (according to Kaufmann et al. 2008, Kenya is in the 15.7 percentile for Rule of Law, with a score of -0.98 on a scale of -2.5 to 2.5), thus we can focus on trust and integrity. One can easily notice the extremely low levels of trust, ranging from -0.7 to -1.0 (on a scale of -1.0 to 2.0 ), which is consistent with the ethno-linguistic fractionalization in Kenya. Integrity levels vary between -0.5 to 0.8 , and therefore allow focusing on integrity and economic performance in a mixed economy, in accordance with proposition 2.

As before, our analysis focuses on correlations. The correlations between integrity and the two leading indicators in Aharonovitz and Kabura (2008), 'electricity, piped water and sewage' and 'house roof' are $\mathbf{- 0 . 2 3}$ and $\mathbf{- 0 . 6 1}$. Thus, similarly to the previous subsection, higher levels of integrity lead to poorer economic performance, as predicted by proposition 2. The correlations with the other indicators are in-line with this proposition as well: a correlation of $\mathbf{0 . 1 4}$ with 'infant mortality rate' (i.e., higher integrity is associated with higher mortality rate), $\mathbf{- 0 . 7 7}$ with 'education' (i.e., higher integrity is inversely associated with higher level of education), $\mathbf{- 0 . 4 2}$ with 'family size' (i.e., integrity is inversely associated with having a smaller family), and $\mathbf{- 0 . 0 5}$ with 'external employment'. Thus, all the correlations are in line with the proposition. As before, we are forced to refrain from regression analysis of Kenya since we have only seven observations, but present such an analysis for Lebanon and Kenya together.

\subsection{Regression analysis}

Due to the number of observations in each country (5 in Lebanon and 7 in Kenya), regression analysis for each country separately is not possible. However, using both countries would yield 12 observations, allowing for basic OLS regressions. One issue that requires attention is the consistency of the variables in both countries. While our index of integrity is consistent in both countries, our measurement of economic well being is not, since we measured education, housing and income deprivation in Lebanon (see table 1), compared to six different categories of well being in Kenya (see table 3). Accordingly, we converted the indicators for Lebanon to well-being indicators on a scale of $0-100$, measuring the share of population above deprivation (i.e., 100 - (deprivation indicator)). For Kenya, all the indicators measured well being on a scale of 0-100, 
besides infant mortality, that was converted to the share on infants surviving (i.e., 100 (mortality rate)).

We used these well-being indicators to construct 4 different well being indicators jointly for the two countries, that are later used in the regression analysis: (1) Housing well being, based on the housing indicator for the ethnic groups in Lebanon and the Electricity, Piped Water and Sewage and House Roof for the tribes in Kenya (which Aharonovitz and Kabura, 2008, find as the most appropriate well being indicator for tribes in Kenya). (2) Housing and education, based on Housing and Education indicators for Lebanon and the Electricity, Piped Water and Sewage, House Roof and Education indicators for Kenya. (3) All but mortality: based on all our available indicators for both countries, besides infant survival rate, which is strongly affected by foreign aid). And (4) All categories indicator, based on all our available indicators for each of the countries. A country dummy variable in the regression will solve the problem of 'level' difference between the groups in each of the countries due to the different sources for the indicators.

According to proposition 2, since both countries are heterogeneous with respect to integrity, and lack proper institutions and trust, integrity of each group should negatively affect its economic well being. The estimated equation is, therefore, economic well being e $_{i}=\alpha+\beta \times$ integrity $_{i}+\gamma \times$ country dummy $_{i}+\varepsilon_{i}$, and we expect $\beta$ to be negative. As mentioned above, we have 12 observations (5 ethnic groups from Lebanon and 7 from Kenya), and four potential indicators for economic well being. The country dummy (i.e., 1 for Kenya and 0 for Lebanon) was used to control for level difference among the two countries, due to the different sources for well being indicators and due to different macroeconomic conditions in the two countries. Table 4 presents the results.

Columns (1)-(4) presents the regressions for each of the indicators mentioned above. The adjusted R-square is relatively high (0.74-0.84). The Kenya dummy is negative in all the regressions (representing either lower levels of well being or indicators which are more demanding, thus reporting lower values for the same well being compared to Lebanon). Our coefficient of interest, measuring the effect of integrity, is negative and significant in all the regressions, ranging from -11.08 to -13.26 , with a significance level of $10 \%$ in one regression and $5 \%$ in the rest. Increasing the index of 
integrity, which ranges from -1 to 2, by 1 unit, translates to a decline of the well being indicator by 11.08 - 13.26, confirming our prediction that in heterogeneous societies with respect to integrity, integrity negatively affects economic performance.

Table 4 - OLS Regression for Economic Performance and Integrity

\begin{tabular}{lcccc}
\hline & $(1)$ & $(2)$ & $(3)$ & $(4)$ \\
\hline Dependent variable & $\begin{array}{c}\text { Housing } \\
\text { indicator }\end{array}$ & $\begin{array}{c}\text { Housing } \\
\text { Education } \\
\text { indicator }\end{array}$ & $\begin{array}{c}\text { All but } \\
\text { mortality } \\
\text { indicator }\end{array}$ & $\begin{array}{c}\text { All } \\
\text { categories } \\
\text { indicator }\end{array}$ \\
\hline Constant & 81.15 & 77.37 & 71.16 & 70.69 \\
& $(14.39)^{* * *}$ & $(16.00)^{* * *}$ & $(14.54)^{* * *}$ & $(14.96)^{* * *}$ \\
Integrity & -11.73 & -13.26 & -11.71 & -11.08 \\
& $(2.05)^{*}$ & $(2.71)^{* *}$ & $(2.36)^{* *}$ & $(2.31)^{* *}$ \\
Kenya Dummy & -39.55 & -30.47 & -30.02 & -37.45 \\
& $(6.42)^{* * *}$ & $(5.77)^{* * *}$ & $(5.61)^{* * *}$ & $(7.25)^{* * *}$ \\
\hline Adjusted R square & 0.80 & 0.75 & 0.74 & 0.84 \\
\hline
\end{tabular}

Numbers in parentheses are the absolute values of the t-statistics.

$*$, **, *** represent significance at $10 \%, 5 \%$ and $1 \%$ levels.

We are aware that using 12 observations cannot serve as a proof, and therefore regard our result merely as some support for the theoretical conclusion. Furthermore, we are aware that the geographical segregation we relied upon to construct the economic performance data is incomplete, that having more surveys and stories would have improved our measurement of the values, and that many other variables should be included in the above regressions as controls (for example, savings rate in each ethnic group; however, both the unavailability of this data and the fact that we have only 12 observations prevent us from including them). As for endogeneity, we iterate our claim from before, that the integrity variable is based on stories that generally predate the economic well being indicators, and therefore economic well being cannot affect our measurement of integrity. We hope to be able to extend our sample in the future, and thus to provide an empirical proof rather than some support.

\section{Discussion}

This research investigates the importance of the individual's values to the economic performance of the individual and the society. We have presented a model of a transactions-based economy with a possible contract prior to every transaction, in which transactions between individuals may lead to growth, but the lack of transactions may 
lead to stagnation or deterioration. We have introduced institutions, social norms leading to trust, and integrity into the model, showing that any one of the three can support better economic performance. We support one of the conclusions of the model, regarding the performance of agents in a heterogeneous economy with respect to integrity, by constructing data for economic performance, integrity and trust for religious groups in Lebanon, while avoiding problems of endogeneity among economic performance and values, and presenting regressions of economic performance as a function of integrity based on this data and similar data for ethnic groups in Kenya.

This transaction based micro-macro model has a potential for analysis of various aspects of institutions, social norms and values. As the nuclear transaction is intuitive on the one hand, but includes prior bargaining and contract, which make is realistic, on the other hand, it is easy to introduce the effects of all the above into this transaction. The introduction of capital into the model allows for aggregating over the transactions and analyzing their effect over the evolution of the entire economy. Another contribution of this paper is constructing data of economic performance for religious groups in Lebanon, which may allow for better understanding of the internal conflict there, as well as constructing data of various values of these groups, which support the methodology for inferring the values and may be used for further research.

The conclusion of the model regarding the successes of an economy with honest agents, and the possible deterioration of a heterogeneous economy (with respect to integrity) as well as the deterioration of an economy with only dishonest agents, economies in which many potential transactions are not executed, has important policy implications. In a less developed country with a high level of integrity, transactions and economic activity can occur without institutions. Aid can be directed at infrastructure, education etc., and succeed in promoting growth, while constructing proper institutions is less important. In less developed economies in which integrity and trust are absent, financing and building proper institutions, such as a strong law enforcement entity, may be required to support transactions. This policy may succeed in an economy with mixed agents, where proper incentives and screenings can ensure that the law enforcement entity would be comprised of honest agents. However, in a country with pure dishonest population, this policy would probably fail, since the law enforcement entity itself would 
be comprised of dishonest agents, and thus would be corrupted and would not ensure contract enforceability. Thus, countries with similar economic characteristics may require different development policies, based on the underlying values leading to the poor economic performance.

We acknowledge several limitations of the empirical part of the present study, including: (1) Having only five groups in Lebanon (and seven for Kenya), with different well being indicators in each country, weakens the empirical analysis; (2) The economic performance of the various groups is based on geographical segregation, which is not complete; and (3) We support the proposition regarding a mixed economy, but do not possess data to support the propositions regarding the extreme cases of complete honesty or complete dishonesty. However, we do believe that we provide some support for the theory, and a methodology for measurement of values to allow for further empirical analysis. We hope to be able to conduct a broader analysis for a large sample of countries.

The macroeconomic literature avoided treating values for a long time, probably due to the abstract nature of this topic and the lack of data. We hope that this research makes a step in making this analysis more concrete while providing relevant data, and thus supporting further research into the differences between growing and stagnating countries and the proper policies that can assist narrowing this gap. 


\section{Appendix 1}

Value

Hard work

Entrepreneurship

Risk taking

Collaboration

Leading others

Altruism

Integrity

Trust

Responsibility

to other group

members

Law obedience

Just reward

Justice \morality

\section{Identifying Question*}

Does the story advocate hard work?

Or - just the opposite (the story advocates being lazy)

Does the story promote entrepreneurship, initiating new activities etc.?

Or - just the opposite (the story discourages entrepreneurship and new initiatives).

Does the story encourage taking risks?

Or - just the opposite (the story encourages avoiding risks).

Does the story promote collaboration with others?

Or - just the opposite (the story promotes individualism and working on one's own).

Does the story encourage leading others?

Or - just the opposite (the story encourages avoiding being a leader).

Does the story advocate good will, altruism, helping others without receiving immediate benefit or preferring someone else's needs over one's own?

Or - just the opposite (the story advocates selfish behavior or discourages altruism).

Does the story promote integrity, telling the truth and being honest in dealing with others?

Or - just the opposite (the story promotes lying and being dishonest).

Does the story encourage trusting others?

Or - just the opposite (the story encourages suspicious and careful behavior towards others).

Does the story promote being responsible and caring to other group members, or doing what others are expecting us to do?

Or - just the opposite (the story promotes rebelling in one's community or society).

Does the story encourage obeying the law and respecting the rules?

Or - just the opposite (the story encourages cheating, stealing or other unlawful behavior, semi-illegal or illegal activities).

Does the story advocate just reward - reward for good deeds or punishment for bad deeds?

Or - just the opposite (the story shows that bad deeds may get a reward while good deeds may bring upon a punishment).

Does the story encourage justice and being just and moral?

Or - just the opposite (the story encourages unjust behavior).

\footnotetext{
*Answers included yes-definitely, yes-somewhat, no, just the opposite or N\A.
} 


\section{References}

Aharonovitz, G. D., Kabura, E., 2008. Values and Economic Performance: Theory and some Evidence from Kenya. SES Working paper.

Akerlof, G. A., 1970. The Market for "Lemons": Quality Uncertainty and the Market Mechanism. Quarterly Journal of Economics 84(3): 488-500.

Akerlof, G. A., 2007. The Missing Motivation in Macroeconomics. American Economic Review 97(1): 5-36.

Albrecht, M. C., 1956. Does Literature Reflect Common Values?. American Sociological Review 21(6): 722-29.

Alesina, A., Giuliano, P., 2007. The Power of the Family. NBER working paper \#w13051.

Axelrod, R. M., 1984. The Evolution of Cooperation. New York, NY: Basic Books.

Axelrod, R. M., 1997. The Complexity of Cooperation: Agent-based Models of Competition and Collaboration. Princeton, NJ: Princeton University Press.

El-Khoury, M., Panizza, U., 2005. Social Mobility and Religion: Evidence from Lebanon. Research in the Social Scientific Study of Religion 16: 133-60.

Friedman, D., 1998. On Economic Applications of Evolutionary Game Theory. Journal of Evolutionary Economics 8(1): 15-43.

Gintis, H., 2007. The Evolution of Private Property. Journal of Economic Behavior and Organization 64(1): 1-16.

Guiso, L., Sapienza, P., Zingales, L., 2004. Cultural Biases in Economic Exchange. NBER working paper \#w11005.

Guiso, L., Sapienza, P., Zingales, L., 2006. Does Culture Affect Economic Outcomes? Journal of Economic Perspectives 20(2): 23-48.

Greif, A., 1993. Contract Enforceability and Economic Institutions in Early Trade: The Maghribi Traders' Coalition. American Economic Review 83(3): 525-48.

Hakemulder, J., 2000. The Moral Laboratory: Experiments Examining the Effects of Reading Literature on Social Perception and Moral Self-concept. Amsterdam/Philadelphia: John Benjamins Publishing Company.

Hall, R. E., Jones, C. I., 1999. Why Do Some Countries Produce So Much More Output per Worker than Others? Quarterly Journal of Economics 114(1): 83-116

Hofstede, G., 2001. Culture's Consequences. Beverly Hills, CA: Sage.

Huang, R. R., 2008. Tolerance for Uncertainty and the Growth of Informationally Opaque Industries. Journal of Development Economics 87(2): 333-53.

Johns-Heine, P., Gerth, H. H., 1949. Values in Mass Periodical Fiction, 1921-1940. Public Opinion Quarterly 13(1): 105-13. 
Kaufmann, D., Kraay, A., Mastruzzi, M., 2008. Governance Matters VII: Aggregate and Individual Governance Indicators, 1996-2007. World Bank Policy Research Working Paper 4654.

Knack, S., Keefer, P., 1995. Institutions and Economic Performance: Cross-Country Tests using Alternative Institutional Measures. Economics and Politics 7(3): 207-27.

Knack, S., Keefer, P., 1997. Does Social Capital Have An Economic Payoff? A CrossCountry Investigation. Quarterly Journal of Economics 112(4): 1251-88.

Licht, A. N., Goldschmidt, C., Schwartz, S. H., 2007. Culture Rules: The Foundations of the Rule of Law and Other Norms of Governance. Journal of Comparative Economics 35(4): 659-88.

McClelland, D. C., 1961. The Achieving Society. Princeton, NJ: Van Nostrand Reinhold.

Mortensen, D. T., Pissarides, C. A., 1994. Job Creation and Job Destruction in the Theory of Unemployment. Review of Economic Studies 61(3): 397-415.

North, D. C., 1990. Institutions, Institutional Change and Economic Performance. New York: Cambridge University Press.

Rabin, M., 1993. Incorporating Fairness into Game Theory and Economics. American Economic Review 83(5): 1281-1302.

Samuelson, L., 2002. Evolution and Game Theory. Journal of Economic Perspectives 16(2): 47-66.

Tabellini, G., 2005. Culture and Institutions: Economic Development in the Regions of Europe. CESifo Working Paper \#1492.

Tabellini, G., 2008a. Institutions and Culture. Journal of the European Economic Association 6(2-3): 255-94.

Tabellini, G., 2008b. The Scope of Cooperation: Values and Incentives. Quarterly Journal of Economics 123(3): 905-50.

United Nations Development Program and Ministry of Social Affairs (Lebanon), 2001. Demographic Characteristics and Socio-Economic Situation in Lebanon. District Booklets 1-26 (in Arabic). Beruit: Ministry of Social Affairs.

Vitz, P., 1990. The Use of Stories in Moral Development: New Psychological Reasons for an Old Education Method. American Psychologist 45(6): 709-20.

Wheaton, W. C., 1990. Vacancy, Search, and Prices in Housing Market Matching Model. Journal of Political Economy 98(6): 1270-92.

Zak, P. J., Knack, S., 2001. Trust and Growth. The Economic Journal 111(470): 295321. 


\section{CESifo Working Paper Series}

for full list see www.cesifo-group.org/wp

(address: Poschingerstr. 5, 81679 Munich, Germany, office@cesifo.de)

2669 Aleksandra Riedl and Silvia Rocha-Akis, Testing the Tax Competition Theory: How Elastic are National Tax Bases in OECD Countries?, June 2009

2670 Dominique Demougin and Carsten Helm, Incentive Contracts and Efficient Unemployment Benefits, June 2009

2671 Guglielmo Maria Caporale and Luis A. Gil-Alana, Long Memory in US Real Output per Capita, June 2009

2672 Jim Malley and Ulrich Woitek, Productivity Shocks and Aggregate Cycles in an Estimated Endogenous Growth Model, June 2009

2673 Vivek Ghosal, Business Strategy and Firm Reorganization under Changing Market Conditions, June 2009

2674 Francesco Menoncin and Paolo M. Panteghini, Retrospective Capital Gains Taxation in the Real World, June 2009

2675 Thomas Hemmelgarn and Gaëtan Nicodème, Tax Co-ordination in Europe: Assessing the First Years of the EU-Savings Taxation Directive, June 2009

2676 Oliver Himmler, The Effects of School Competition on Academic Achievement and Grading Standards, June 2009

2677 Rolf Golombek and Michael Hoel, International Cooperation on Climate-Friendly Technologies, June 2009

2678 Martin Cave and Matthew Corkery, Regulation and Barriers to Trade in Telecommunications Services in the European Union, June 2009

2679 Costas Arkolakis, A Unified Theory of Firm Selection and Growth, June 2009

2680 Michelle R. Garfinkel, Stergios Skaperdas and Constantinos Syropoulos, International Trade and Transnational Insecurity: How Comparative Advantage and Power are Jointly Determined, June 2009

2681 Marcelo Resende, Capital Structure and Regulation in U.S. Local Telephony: An Exploratory Econometric Study; June 2009

2682 Marc Gronwald and Janina Ketterer, Evaluating Emission Trading as a Policy Tool Evidence from Conditional Jump Models, June 2009

2683 Stephan O. Hornig, Horst Rottmann and Rüdiger Wapler, Information Asymmetry, Education Signals and the Case of Ethnic and Native Germans, June 2009 
2684 Benoit Dostie and Rajshri Jayaraman, The Effect of Adversity on Process Innovations and Managerial Incentives, June 2009

2685 Peter Egger, Christian Keuschnigg and Hannes Winner, Incorporation and Taxation: Theory and Firm-level Evidence, June 2009

2686 Chrysovalantou Milliou and Emmanuel Petrakis, Timing of Technology Adoption and Product Market Competition, June 2009

2687 Hans Degryse, Frank de Jong and Jérémie Lefebvre, An Empirical Analysis of Legal Insider Trading in the Netherlands, June 2009

2688 Subhasish M. Chowdhury, Dan Kovenock and Roman M. Sheremeta, An Experimental Investigation of Colonel Blotto Games, June 2009

2689 Alexander Chudik, M. Hashem Pesaran and Elisa Tosetti, Weak and Strong Cross Section Dependence and Estimation of Large Panels, June 2009

2690 Mohamed El Hedi Arouri and Christophe Rault, On the Influence of Oil Prices on Stock Markets: Evidence from Panel Analysis in GCC Countries, June 2009

2691 Lars P. Feld and Christoph A. Schaltegger, Political Stability and Fiscal Policy - Time Series Evidence for the Swiss Federal Level since 1849, June 2009

2692 Michael Funke and Marc Gronwald, A Convex Hull Approach to Counterfactual Analysis of Trade Openness and Growth, June 2009

2693 Patricia Funk and Christina Gathmann, Does Direct Democracy Reduce the Size of Government? New Evidence from Historical Data, 1890-2000, June 2009

2694 Kirsten Wandschneider and Nikolaus Wolf, Shooting on a Moving Target: Explaining European Bank Rates during the Interwar Period, June 2009

2695 J. Atsu Amegashie, Third-Party Intervention in Conflicts and the Indirect Samaritan's Dilemma, June 2009

2696 Enrico Spolaore and Romain Wacziarg, War and Relatedness, June 2009

2697 Steven Brakman, Charles van Marrewijk and Arjen van Witteloostuijn, Market Liberalization in the European Natural Gas Market - the Importance of Capacity Constraints and Efficiency Differences, July 2009

2698 Huifang Tian, John Whalley and Yuezhou Cai, Trade Sanctions, Financial Transfers and BRIC's Participation in Global Climate Change Negotiations, July 2009

2699 Axel Dreher and Justina A. V. Fischer, Government Decentralization as a Disincentive for Transnational Terror? An Empirical Analysis, July 2009

2700 Balázs Égert, Tomasz Koźluk and Douglas Sutherland, Infrastructure and Growth: Empirical Evidence, July 2009 
2701 Felix Bierbrauer, Optimal Income Taxation and Public Goods Provision in a Large Economy with Aggregate Uncertainty, July 2009

2702 Marc Gronwald, Investigating the U.S. Oil-Macroeconomy Nexus using Rolling Impulse Responses, July 2009

2703 Ali Bayar and Bram Smeets, Government Deficits in the European Union: An Analysis of Entry and Exit Dynamics, July 2009

2704 Stergios Skaperdas, The Costs of Organized Violence: A Review of the Evidence, July 2009

2705 António Afonso and Christophe Rault, Spend-and-tax: A Panel Data Investigation for the EU, July 2009

2706 Bruno S. Frey, Punishment - and beyond, July 2009

2707 Michael Melvin and Mark P. Taylor, The Crisis in the Foreign Exchange Market, July 2009

2708 Firouz Gahvari, Friedman Rule in a Model with Endogenous Growth and Cash-inadvance Constraint, July 2009

2709 Jon H. Fiva and Gisle James Natvik, Do Re-election Probabilities Influence Public Investment?, July 2009

2710 Jarko Fidrmuc and Iikka Korhonen, The Impact of the Global Financial Crisis on Business Cycles in Asian Emerging Economies, July 2009

2711 J. Atsu Amegashie, Incomplete Property Rights and Overinvestment, July 2009

2712 Frank R. Lichtenberg, Response to Baker and Fugh-Berman's Critique of my Paper, "Why has Longevity Increased more in some States than in others?", July 2009

2713 Hans Jarle Kind, Tore Nilssen and Lars Sørgard, Business Models for Media Firms: Does Competition Matter for how they Raise Revenue?, July 2009

2714 Beatrix Brügger, Rafael Lalive and Josef Zweimüller, Does Culture Affect Unemployment? Evidence from the Röstigraben, July 2009

2715 Oliver Falck, Michael Fritsch and Stephan Heblich, Bohemians, Human Capital, and Regional Economic Growth, July 2009

2716 Wladimir Raymond, Pierre Mohnen, Franz Palm and Sybrand Schim van der Loeff, Innovative Sales, R\&D and Total Innovation Expenditures: Panel Evidence on their Dynamics, July 2009

2717 Ben J. Heijdra and Jochen O. Mierau, Annuity Market Imperfection, Retirement and Economic Growth, July 2009 
2718 Kai Carstensen, Oliver Hülsewig and Timo Wollmershäuser, Price Dispersion in the Euro Area: The Case of a Symmetric Oil Price Shock, July 2009

2719 Katri Kosonen and Gaëtan Nicodème, The Role of Fiscal Instruments in Environmental Policy, July 2009

2720 Guglielmo Maria Caporale, Luca Onorante and Paolo Paesani, Inflation and Inflation Uncertainty in the Euro Area, July 2009

2721 Thushyanthan Baskaran and Lars P. Feld, Fiscal Decentralization and Economic Growth in OECD Countries: Is there a Relationship?, July 2009

2722 Nadia Fiorino and Roberto Ricciuti, Interest Groups and Government Spending in Italy, 1876-1913, July 2009

2723 Andreas Wagener, Tax Competition, Relative Performance and Policy Imitation, July 2009

2724 Hans Fehr and Fabian Kindermann, Pension Funding and Individual Accounts in Economies with Life-cyclers and Myopes, July 2009

2725 Ernesto Reuben and Arno Riedl, Enforcement of Contribution Norms in Public Good Games with Heterogeneous Populations, July 2009

2726 Kurt Schmidheiny and Marius Brülhart, On the Equivalence of Location Choice Models: Conditional Logit, Nested Logit and Poisson, July 2009

2727 Bruno S. Frey, A Multiplicity of Approaches to Institutional Analysis. Applications to the Government and the Arts, July 2009

2728 Giovanni Villani, A Strategic R\&D Investment with Flexible Development Time in Real Option Game Analysis, July 2009

2729 Luca Di Corato and Michele Moretto, Investing in Biogas: Timing, Technological Choice and the Value of Flexibility from Inputs Mix, July 2009

2730 Gilad D. Aharonovitz, Nathan Skuza and Faysal Fahs, Can Integrity Replace Institutions? Theory and Evidence, July 2009 